\title{
Fibre supplementation increased the risk for recurrent adenomas, and calcium supplementation did not prevent recurrence
}

\author{
Bonithon-Kopp C, Kronborg O, Giacosa A, et al, for the European Cancer Prevention Organisation Study Group. Calcium and \\ fibre supplementation in prevention of colorectal adenoma recurrence: a randomised intervention trial. Lancet 2000 Oct \\ 14;356:1300-6.

\section{QUESTION: In patients with colorectal adenomas, does supplementation with ispaghula husk or calcium prevent adenoma recurrence?}

\section{Design}

Randomised (allocation concealed*), blinded (patients, clinical staff, and investigators),* placebo controlled trial with 3 years follow up.

\section{Setting}

21 centres in 10 countries (Belgium, Denmark, France, Germany, Ireland, Israel, Italy, Portugal, Spain, and the UK).

\section{Patients}

665 patients who were $35-75$ years of age, had a complete index colonoscopy showing $\geqslant 2$ adenomas or 1 adenoma of $>5 \mathrm{~mm}$ in diameter, and did not have a debilitating or life threatening disease. Exclusion criteria were history of large bowel disease, contraindications to calcium or fibre, or inability or unwillingness to stop current fibre or calcium supplementation. 552 patients $(83 \%$, mean age $59 \mathrm{y}, 64 \%$ men) completed the 3 year follow up.

\section{Intervention}

After stratification by centre, patients were allocated to 1 of 3 groups: elemental calcium, given at $2 \mathrm{~g}$ of calcium gluconolactate and carbonate in a water solution twice daily $(\mathrm{n}=176)$; ispaghula husk, given as $3.5 \mathrm{~g}$ of orange flavoured effervescent granules dissolved in water $(n=198)$; or placebo that either matched the elemental calcium or the ispaghula husk $(\mathrm{n}=178)$.

\section{Main outcome measure}

New adenomas at the 3 year colonoscopy.

\section{Main results}

Patients in the fibre group had a $45 \%$ increase in recurrent adenomas relative to the placebo group at 3 years $\{\mathrm{p}=0.04\} \uparrow$ (table). The difference between the calcium and placebo groups was not statistically significant (table).

\section{Conclusions}

In patients with adenomas, supplementation with ispaghula husk increased the risk for recurrent adenoma. Calcium supplementation did not prevent adenomas.

*See glossary.

$\dagger \mathrm{p}$ Value calculated from data in article.

Tumori Genova.

Supplementation with calcium or ispaghula husk (fibre) v placebo for preventing recurrent adenomas:

For correspondence:

Pefessor J Faive,

Registre Bourguignon

des Tumeurs Digestives,

Faculté de Médecine de

Dijon, BP 87900,

21079 Dijon, France.

Fax +3338066

8251 .

\begin{tabular}{lllll}
\hline Outcome at 3 years & Comparison & Event rates & RRI (95\% Cl) & NNH (Cl) \\
Recurrent adenomas & Fibre $v$ placebo & $29 \% v 20 \%$ & $45 \%(1$ to 109$)$ & $12(6$ to 340$)$ \\
RRR (Cl) & NNT & Not significant \\
\hline
\end{tabular}

¥Abbreviations defined in glossary; RRI, RRR, NNH, NNT, and Cl calculated from data in article

\section{COMMENTARY}

The tendency to develop colorectal cancer is largely acquired, although genes play a part in some people. Age adjusted incidence rates vary 10 to 15 -fold throughout the world, and people who move from low to high incidence areas, such as North America and Europe, acquire higher rates during their lifetimes. Observational studies suggest that calcium and fibre are protective along with other factors, ${ }^{1}$ but this has been difficult to confirm because of the limitations of observational studies, especially the lack of ability to measure long term dietary exposure.

The randomised trial by Bonithon-Kopp et al ought to settle the matter. But does it? The trial has limitations, which are common even in the best preventive trials. The results are imprecise because enrolment was lower than the investigators had planned. The main outcome event was recurrence of adenomas, but a different set of factors may govern their growth, evolution to cancer, and distant spread. Many participants did not cooperate with their assigned treatment, leaving room for systematic differences among compared groups despite initial randomisation. Finally, 3 years of follow up is a short time in the natural history of this cancer, which usually takes at least 10 years to develop. With this study, the benefits of calcium supplementation look more promising, whereas fibre supplementation looks less promising. But that is a matter for investigators in this difficult field to tackle. Clinicians should still advise patients to consume $\geqslant 5$ vegetables and fruits, a multivitamin, and calcium supplements each day. This practice may not only help to prevent colorectal cancer but also is advisable for many other health reasons.

Robert H Fletcher, MD, MSc Harvard Medical School Boston, Massachusetts, USA

1 Tomeo CA, Colditz GA, Willett WC, et al. Harvard report on cancer prevention. Volume 3: prevention of colon cancer in the United States. Cancer Causes Control 1999;10:167-80 